\title{
Interference of propylene glycol with the hole-board test
}

A. Lourenço da Silva ${ }^{1}$ and E. Elisabetsky ${ }^{1,2}$
${ }^{1}$ Curso de Pós-Graduação em Ciências Biológicas-Bioquímica and

${ }^{2}$ Departamento de Farmacologia, Instituto de Ciências Básicas da Saúde, Universidade Federal do Rio Grande do Sul, Porto Alegre, RS, Brasil

\section{Correspondence \\ E. Elisabetsky \\ Caixa Postal 5072 \\ 90041-970 Porto Alegre, RS \\ Brasil \\ E-mail: elisasky@ vortex.ufrgs.br}

Research supported by CNPq (No. 522912/96.6), FAPERGS

(No. 98/1610.3) and PRO PESQ (No. 25/00).

Received August 21, 2000

Accepted February 5, 2001

\section{Abstract}

Experimental drugs and/or plant extracts are often dissolved in solvents, including propylene glycol. Nevertheless, there is evidence for psychoactive properties of this alcohol. In this study we found that in the hole-board test $10 \%$ propylene glycol did not modify the headdipping behavior. However, 30\% propylene glycol induced an increase in the number of head-dips (46.92 \pm 2.37 compared to $33.83 \pm$ 4.39, $\mathrm{P}<0.05$, ANOVA/Student-Newman-Keuls), an effect comparable to that obtained with $0.5 \mathrm{mg} / \mathrm{kg}$ diazepam (from $33.83 \pm 4.39$ to $54 \pm 3.8, \mathrm{P}<0.01$, ANOVA/Student-Newman-Keuls). These results demonstrate that $30 \%$ propylene glycol has significant anxiolytic effects in this model and therefore cannot be used as an innocuous solvent.

Solvents are frequently used as vehicles for experimental drugs and/or plant extracts that cannot be dissolved in water or saline. Among solvents, propylene glycol (PPG) is fairly commonly used in experimental pharmacology and toxicology. PPG is also often used as excipient in injectable formulations including anxiolytics (e.g., in Brazil, Diazepam N.Q. ${ }^{\circledR}$ (Novaquímica), Contaz (Cristália), Diazepam (Eurofarma), Diazepam (União Química), Diazepam (Vital Brazil), and Somaplus (Cazi)).

Indications that PPG is active in the central nervous system have been reported. PPG (ip) at concentrations of 50 to $100 \%$ produced a moderate to marked decrease in spontaneous motor activity, body and limb tone, and respiration; moreover, $60 \%$ of the animals showed ptosis and ataxia. However, these effects were found to be negligible at lower concentrations (10 to 20\%) (1). While clonazepam dissolved in PPG did not significantly protect cats from high-pressure oxygen-induced convulsions, PPG alone at doses of $0.1-0.2 \mathrm{ml} / \mathrm{kg}(p o)$ did offer significant protection (2). An increase in the number of open arm entries and head-dips in male mice that received PPG at doses of 27 to $41 \mathrm{mmol} /$ $\mathrm{kg}$ ( $p o$ ) (approximately 20 to $30 \%$ ) in the elevated plus-maze test has been recently reported (3). These data provide evidence for the anxiolytic properties of this alcohol.

The hole-board has gained popularity as a model of anxiety, offering "a simple method for measuring the response of an animal to an unfamiliar environment, with advantages that several behaviors can be readily observed and quantified in this test" (4). The purpose of the present paper is to report the effects of PPG in the hole-board model, as a cautionary 
note about the use of PPG as solvent in this model.

Experiments were performed with male adult (CF1) mice received from Fundação Estadual de Experimentação e Produção da Saúde immediately after weaning (21 days). Animals were maintained in our own animal facilities in a controlled environment $(22 \pm$ $1{ }^{\circ} \mathrm{C}, 12$-h light/dark cycle, free access to food (Nuvilab CR1) and water) up to 10 weeks old (25-40 g). Diazepam and PPG were acquired from Sigma Chemical Co., St. Louis, MO, USA. Vehicle concentration is reported as percent in $0.9 \% \mathrm{NaCl}$ (saline). Diazepam at a concentration of $0.5 \mathrm{mg} / \mathrm{kg}$ was suspended in $10 \%(\mathrm{v} / \mathrm{v})$ or $30 \%(\mathrm{v} / \mathrm{v})$ PPG.

The hole-board apparatus (Ugo Basile, Varese, Italy) consisted of gray Perspex panels $(40 \times 40 \mathrm{~cm}, 2.2 \mathrm{~cm}$ thick) with 16 equidistant holes $3 \mathrm{~cm}$ in diameter in the floor. Photocells below the surface of the holes measured the number of head-dips. The board was positioned $15 \mathrm{~cm}$ above the table and divided into 9 squares of $10 \times 10$ $\mathrm{cm}$ with a water-resistant marker. Mice were

Figure 1 - Effects of diazepam (DZP) and propylene glycol (PPG) on the number of head-dips in the hole-board test. PPG (10\%, PPG10), 30\% PPG (PPG30), and $0.5 \mathrm{mg} / \mathrm{kg}$ diazepam diluted in $10 \%$ PPG (DZP10) or 30\% PPG (DZP30) were used. Each column represents the mean \pm SEM. $* P<0.05$ and $* * P<0.01$ compared to saline (ANOVA).

Figure 2 - Effects of diazepam (DZP) and propylene glycol (PPG) on locomotion (number of squares crossed with all four paws) in the hole-board test. PPG (10\%, PPG10), 30\% PPG (PPG30), $0.5 \mathrm{mg} / \mathrm{kg}$ diazepam diluted in $10 \%$ PPG (DZP10) or $30 \%$ PPG (DZP30) were used. Each column represents the mean \pm SEM. $* P<0.05$ compared to saline (ANOVA).
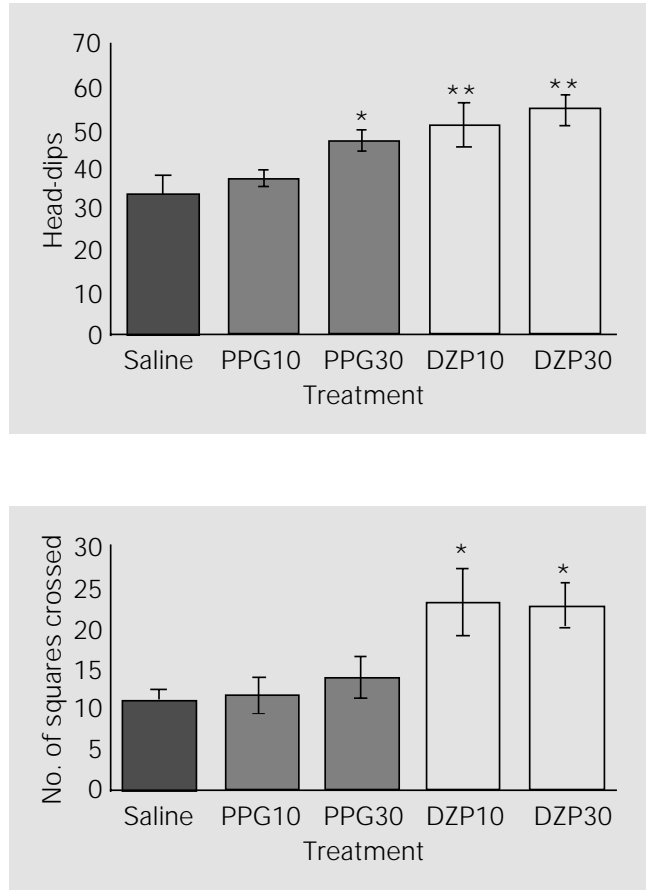

transported to the dimly lit laboratory at least $1 \mathrm{~h}$ prior to testing. Treatments (saline, $10 \%$ PPG, $30 \%$ PPG, $0.5 \mathrm{mg} / \mathrm{kg}$ diazepam solubilized in 10 or $30 \%$ PPG) were administered ip, $10 \mathrm{ml} / \mathrm{kg}, 30 \mathrm{~min}$ prior to testing $(\mathrm{N}=10$ 12 /group). Each animal was placed singly in the center of the board facing away from the observer and its behavior recorded for $5 \mathrm{~min}$; the latency to the first head-dip was measured using a stopwatch (5). Rearing, grooming, number of defecations and spontaneous movements (number of squares crossed with all four paws) were also recorded. Results are reported as means $\pm \mathrm{SEM}$. The numbers of head-dips, rearing, grooming, spontaneous movements and latency were analyzed by ANOVA followed by the Student-Newman-Keuls test.

Head-dip results are shown in Figure 1. Diazepam $(0.5 \mathrm{mg} / \mathrm{kg})$ dissolved in 10 or $30 \%$ PPG significantly increased the number of head-dips in comparison to saline or $10 \%$ PPG $(\mathrm{P}<0.01)$. PPG $(10 \%)$ did not modify the head-dipping behavior. However, $30 \%$ PPG alone induced an increase in headdips in comparison with saline $(\mathrm{P}<0.05)$, i.e., an increase comparable to that induced by diazepam. Data about spontaneous locomotion (number of squares crossed with all four paws) are presented in Figure 2. Regardless of the PPG concentration used in the solution, locomotion increased in animals treated with diazepam $(0.5 \mathrm{mg} / \mathrm{kg})$ in comparison with saline, $10 \%$ PPG or $30 \%$ PPG. PPG alone did not influence locomotion. Neither diazepam nor PPG significantly altered the number of rearing, grooming, or defecation events or latency to first head-dip (data not shown).

The present study showed that $0.5 \mathrm{mg} / \mathrm{kg}$ diazepam increases head-dipping and locomotion of mice in the hole-board test. It has been previously reported (4) that diazepam increases head-dipping behavior at doses similar to those used in this study, although the authors did not observe modifications in locomotor activity with $0.5 \mathrm{mg} / \mathrm{kg}$. Several 
studies have reported that diazepam increases locomotor activity in the open field (6-8). Moreover, increases in number of squares crossed in the open field and in head-dips in the hole-board were obtained with desmethyldiazepam and chlordesmethyldiazepam (9). Our results indicate that this non-sedative but anxiolytic dose of diazepam facilitates exploratory behavior expressed as increased head-dips and locomotion.

The significant new finding of this study is that $30 \%$ PPG alone increases head-dip behavior. PPG, 10 or $30 \%$, did not affect any of the other parameters observed. Although toxicity studies showed that toxic PPG doses are much higher than those used in this study $(10,11)$, our results showed that $30 \%$ PPG can interfere with results obtained with the hole-board model. The data are in agreement with previous results (3) indicating that $10 \%$ is the limiting concentration of PPG as an inert solvent in the elevated plus-maze test.

The data reported here are of relevance in selecting vehicles for screening candidate compounds for new sedative drugs (e.g., 12), since they indicate that PPG does interfere with the hole-board model. The data also indicate that caution is necessary when using PPG as excipient in pharmaceutical products.

\section{References}

1. Singh PP, J unnarkar AY, Seshagirirao C, Kaushal R, Naidu MU, Varma RK, Tripathi RM \& Shridhar DR (1982). A pharmacological study of propane-1,2-diol. Arzneimittel-Forschung (Drug Research), 32: 1443-1446.

2. Beckman DL \& Crittenden DJ (1981). Protection from oxygen-induced seizures by clonazepam and propylene glycol. Proceedings of the Society for Experimental Biology and Medicine, 168: 45-48.

3. Lin HQ, Burden PM \& J ohnston GAR (1998). Propylene glycol elicits anxiolyticlike responses to the elevated plus-maze in male mice. J ournal of Pharmacy and Pharmacology, 50: 1127-1131.

4. Takeda H, Tsuji M \& Matsumiya T (1998). Changes in head-dipping behavior in the hole-board test reflect the anxiogenic and/ or anxiolytic state in mice. European J ournal of Pharmacology, 350: 21-29.

5. File SE \& Pellow S (1985). The effects of triazolobenzodiazepines in two animal tests of anxiety and in the holeboard. British J ournal of Pharmacology, 86: 729-735.

6. Wieland S, Lan NC, Mirasedeghi S \& Gee KW (1991). Anxiolytic activity of the progesterone metabolite $5 \alpha$-pregnan-3 $\alpha$-ol20-one. Brain Research, 565: 263-268.

7. Bhattacharya SK \& Mitra SK (1991). Anxiolytic activity of Panax gingeng roots: an experimental study. J ournal of Ethnopharmacology, 34: 87-92.

8. Ramanathan $M$, Jaiswal $A K$ \& Bhattacharya SK (1998). Differential effects of diazepam on anxiety in streptozotocin induced diabetic and non-diabetic rats. Psychopharmacology, 135: 361-367.
9. De Angelis L, Bertolissi M, Nardini G, Traversa U \& Vertua R (1982). Interaction of caffeine with benzodiazepines: behavior effects in mice. Archives Internationales de Pharmacodynamie et de Therapie, 255: 89-102.

10. Davis KJ \& J enner P (1959). Toxicity of three drug solvents. Toxicology and Applied Pharmacology, 1: 576-578.

11. Braak K \& Frey HH (1990). Effects of solvents and detergents on the contractions of isolated smooth muscle preparations. J ournal of Pharmacy and Pharmacology, 42: 837-841.

12. Molina-Hernández $M$, Télles-Alcántara $P$ \& Martínez E (2000). Agastache mexicana may produce anxiogenic-like actions in the male rat. Phytomedicine, 7: 199-203. 